\title{
Pobreza Rural e Degradação Ambiental: uma Refutação da Hipótese do Círculo Vicioso ${ }^{1}$
}

\author{
Paulo D. Waquil ${ }^{2}$ \\ Marcus V. A. Finco ${ }^{3}$ \\ e Ely J. Mattos ${ }^{4}$
}

Resumo - O estudo analisa as relações entre pobreza rural e degradação ambiental, tendo como área de estudo os municípios de Machadinho e Maximiliano de Almeida, na região Noroeste do RS. Com base nas entrevistas com 48 agricultores, foi formado um banco de dados, contemplando vários indicadores sócio-econômicos e ambientais. Foram estimados diversos modelos não-lineares de regressão (probit), tendo variáveis binárias como dependentes, expressando a degradação ambiental, e os diversos indicadores sócio-econômicos como variáveis independentes, expressando as situações de pobreza rural. Os principais resultados sugerem a refutação da hipótese de que pobreza rural e degradação ambiental estão diretamente relacionadas.

\footnotetext{
${ }^{1}$ Este artigo foi elaborado como parte do projeto "Políticas públicas, agricultura familiar e pobreza rural no Rio Grande do Sul”, financiado pela Fundação de Amparo à Pesquisa do Estado do Rio Grande do Sul (FAPERGS).

${ }^{2}$ Doutor em Economia Agrícola. Professor do Departamento de Economia (DECON) e dos Programas de Pós-Graduação em Desenvolvimento Rural (PGDR) e Agronegócios (PPGAN) da UFRGS e bolsista do CNPq.

E-mail: waquil@ufrgs.br

${ }^{3}$ Mestre em Desenvolvimento Rural (PGDR/UFRGS) e pesquisador do Instituto Ecologica (Palmas/TO).

E-mail: marcus.finco@ufrgs.br

${ }^{4}$ Aluno do Curso de Graduação em Economia da UFRGS, bolsista de iniciação científica (PIBIC/CNPq).

E-mail: elymattos@zipmail.com.br
} 
Palavras-chave: pobreza, degradação, indicadores sócio-econômicos, meio ambiente, modelo probit.

Abstract - This study analyses the relationships between rural poverty and environmental degradation in Machadinho and Maximiliano de Almeida, in the state of Rio Grande do Sul, Brazil. A database was formed based on 48 interviews with small farmers, including several environmental and socioeconomic indicators. Non-linear regression (Probit) models were estimated, with dummy variables as dependents, expressing environmental degradation, and the socioeconomic indicators as independent variables, expressing the rural poverty situations. The main results point towards a refutation of the hypothesis that rural poverty and environmental degradation are directly correlated, forming a vicious circle.

Key-words - poverty; environmental degradation; probit models.

Jel Classification: Q24

\section{1 - Introdução}

A preocupação mundial quanto à preservação dos recursos naturais e ambientais atualmente faz com que venham sendo desenvolvidas pesquisas voltadas à identificação das principais causas, dos causadores e das principais conseqüências da degradação do meio ambiente, assim como pesquisas voltadas à busca de alternativas para a resolução dos problemas trazidos pela degradação. Conforme Alier (1998), essa degradação ocorre tanto em países desenvolvidos como em países em desenvolvimento, tanto no meio urbano como no rural, através, sobretudo, da pressão que a produção e a população exercem sobre os bens e serviços gerados pelo uso dos recursos naturais.

Contudo, a questão que envolve a degradação ambiental nos países desenvolvidos cedeu espaço, após o Relatório Brundtland, em 1987, a uma visão de que os países em desenvolvimento exercem um papel na degradação dos recursos naturais e ambientais até mesmo mais expressivo do que os países desenvolvidos. A partir daquele Relatório, conhe- 
cido também como "Nosso Futuro Comum”, a degradação ambiental passou a ser associada ao grau de pobreza da população, resultando em vários estudos que visavam detectar alguma relação entre a condição de pobreza e a degradação do meio ambiente.

Nesta visão, a condição de pobreza rural, além de acelerar a degradação dos recursos naturais, poderia passar a criar, através de um "círculo vicioso", uma situação de perpetuação da sua condição como tal. Discutindo alguns condicionantes da pobreza rural na América Latina, Echeverria (1998, p. 6) alerta que

Una gran mayoría de los pobres rurales vive en áreas de bajo potencial, incluyendo zonas degradadas, erosionadas o semidesérticas, y tierras frágiles y marginales de ladera y humedales. Esta población tiene una gran dependencia en los recursos naturales que son la base de su sustento (agua, alimento, energía e ingreso), pero por las limitantes en cuanto a la calidad y cantidad de estos recursos, cruzan el umbral de sustentabilidad y empiezan, por falta de otra alternativa, a destruir esta base.

Em outra obra, o mesmo autor comenta:

Somente al romperse el círculo de la pobreza y del deterioro de los recursos naturales puede originarse um círculo virtuoso en que la restauración de los recursos naturales contribuye a la reducción de la pobreza, pero para ello es preciso aplicar programas de apoyo que tengan esta finalidad concreta. (Echeverria, 2000, p. 156).

Entretanto, este círculo vicioso entre pobreza e degradação é questionado por alguns autores. Conforme apontado por Broad (1994) e por Reardon e Vosti (1995), o círculo vicioso é analisado tal que a condição de pobreza é retratada através de um conceito único, reduzindo, desta maneira, a abrangência dessa condição de vida. De forma a romper com este conceito, Reardon e Vosti (1995) indicam que a condição de pobreza pode se apresentar de diversas formas, justamente por não possuir uma única concepção. Também a degradação ambiental pode se apresentar de diversas formas, podendo implicar em diferentes relações entre a condição de pobreza e a suposta degradação que esta condição resulta. 
Assim sendo, é importante que as relações entre pobreza rural e degradação ambiental sejam investigadas com maior aprofundamento, nos mais diversos cenários, tornando possível fornecer subsídios para a formulação e implementação de políticas públicas. Neste contexto é que apresentamos o presente artigo, objetivando verificar a hipótese do "círculo vicioso", ou, mais especificamente, analisar as relações entre pobreza e degradação ambiental, nos municípios de Machadinho e Maximiliano de Almeida, na região Noroeste do Rio Grande do Sul.

A fim de capturar a complexidade das relações, procuramos identificar uma série de variáveis sócio-econômicas e ambientais que nos permitissem melhor expressar as condições de pobreza rural e de degradação ambiental na região, nas suas diversas formas e graus. A partir da formação da nossa base de dados, estimamos as relações utilizando um modelo de regressão probit. O artigo, desta forma, foi organizado contemplando um breve referencial teórico, a caracterização da área de estudo e das variáveis utilizadas, o perfil dos agricultores da região, o modelo de regressão utilizado e os resultados obtidos.

\section{2 - Referencial teórico}

Segundo Reardon e Vosti (1995), a relação entre pobreza e degradação ambiental ainda é pouco explorada, de forma sistemática, na literatura. Os autores comentam que o círculo vicioso entre pobreza e degradação ambiental é de inspiração Malthusiana, onde o aumento da população demanda também um aumento na área cultivada com produtos alimentares e empurra cada vez mais os agricultores mais carentes para áreas marginais, acelerando a degradação. A degradação dos recursos naturais e ambientais, por sua vez, reduz a produtividade, resultando em empobrecimento dos agricultores. Este círculo sugere que a redução da pobreza irá, necessariamente, reduzir a degradação do meio ambiente, assim como a conservação e preservação do meio ambiente irá, necessariamente, reduzir a pobreza.

Barbier (2000) reforça esta visão, apresentando evidências de alguns estudos de caso na África. O autor ilustra que a sobreutilização dos recursos naturais causa o declínio da produtividade, forçando a ocupação de novas áreas menos produtivas; sem investimentos adicionais 
na preservação dos recursos, o processo se repete, agravando as situações de pobreza.

Entretanto, algumas lacunas são identificadas por Reardon e Vosti (1995), como: (i) a pobreza é identificada com um conceito único; (ii) não é feita diferenciação dos tipos de degradação dos recursos naturais; (iii) em geral, não são considerados problemas associados à mensuração da pobreza; (iv) a intensidade e a simetria das relações causais são raramente discutidas; e (v) a literatura ainda não trouxe provas (evidências) suficientes que levem ao entendimento da relação entre pobreza e meio ambiente. Os autores sugerem que a relação entre a pobreza rural e a degradação ambiental é complexa, e pode variar de acordo com o tipo de pobreza, bem como com o tipo de problema ambiental que o agricultor se depara (erosão, desertificação, uso de agrotóxico), citando que “(...) the type of poverty can influence the environment-poverty links" e também que "(...) expanding the debate to differentiate between types of environmental problems can have important implications for understanding the links".

Por sua vez, Broad (1994) mostra que a literatura convencional, no campo do desenvolvimento e meio ambiente, freqüentemente apresenta uma visão determinística da relação entre pobreza e meio ambiente, concluindo que há um impacto negativo do primeiro sobre o segundo. Em outras palavras, a pobreza, e os pobres, são vistos como uma das causas primárias da destruição ambiental. Algumas frases como "poverty and environment connection ... inseparable twins", "if one is poor, then one degrades", "poverty is one of the greatest threats to the environment" são mostradas pelo autor como forma de identificar o pensamento do “mainstream" sobre o assunto. Broad (1994), por outro lado, apresenta a crítica da Economia Política ao sentido convencional da relação entre pobreza e meio ambiente, questionando "who protects which environment from whom?”. O autor baseia-se num estudo de caso nas Filipinas, apontando como os pobres podem tornar-se protetores ambientais.

Cavendish (1999) apresenta um estudo que procura identificar a contribuição dos recursos naturais e ambientais na composição da renda dos agricultores, bem como na escolha das atividades desenvolvidas pelos pobres rurais na África. O autor sugere que os pobres são mais 
dependentes dos recursos naturais do que os ricos, ou seja, a parcela da renda advinda da exploração dos recursos naturais diminui quando a renda agregada aumenta. Contudo, os ricos são os que mais utilizam o meio ambiente, de forma absoluta, isto é, embora os pobres necessitem relativamente mais dos recursos naturais para sobreviver, os ricos exploram quantidades muito superiores às quantidades utilizadas pelos agricultores pobres. $\mathrm{O}$ autor conclui que, ao contrário dos resultados sobre a composição da renda, a demanda absoluta pelos recursos ambientais não declina com a renda. Com isso, se aceitarmos o argumento de que quantidades crescentes de demanda pelos recursos naturais e a utilização destes recursos podem causar degradação ambiental, a hipótese de que a pobreza é causa da degradação pode ser refutada.

Por outro lado, Meza, Southgate e Vega (2002) se fundamentam no Relatório Brundtland para sustentar sua hipótese de trabalho. Os autores estudam a relação existente entre a renda e a preservação das florestas. Neste caso, os resultados encontrados sugerem que esta relação é positiva, ou seja, quanto melhor é a relação PNB per capita, melhores são as condições de preservação das florestas. Escolhas individuais como a ocupação de florestas, bem como o tipo de atividade a ser posta em prática depois da ocupação, são influenciadas por diversos fatores como qualidade do solo, arrendamento, acesso a mercado, nível de educação, entre outros. Na conclusão do trabalho, os autores mencionam que quanto mais isolado o agricultor (por falta de estradas, por exemplo), menor a renda deste agricultor e maior a degradação ambiental que ele acarreta. Ao contrário, quanto melhor o capital humano (maior a escolaridade, por exemplo), maior a renda e menor o desmatamento, já que o emprego não-agrícola melhora a diversificação na renda e diminui a propensão de danos às florestas.

Com base nestes estudos, que retratam diversas situações relacionando a pobreza rural e a degradação ambiental, procedemos nossa análise, conforme apresentado a seguir.

\section{3 - Área de estudo e definição da amostra}

Para fazer a pesquisa de campo e formar a nossa base de dados, selecionamos dois municípios no Estado do Rio Grande do Sul, predo- 
minantemente agrícolas e com maior grau de carência sócio-econômica. Tomando como base o estudo desenvolvido por Schneider e Waquil (2001), que caracteriza e faz uma tipologia dos municípios gaúchos utilizando uma série de indicadores sócio-econômicos, optamos pela pesquisa nos municípios de Machadinho e Maximiliano de Almeida, ambos situados na mesorregião Noroeste do Rio Grande do Sul, microrregião de Sananduva, conforme classificação do IBGE.

Os dois municípios são pequenos, com mais da metade da população residindo no espaço rural. Machadinho possui uma área de $333,0 \mathrm{~km}^{2}$ e, segundo os dados do censo demográfico de 2000, tem 5.729 habitantes, sendo que 2.780 vivem no meio urbano e 2.949 no meio rural. Já o município de Maximiliano de Almeida possui 215,5 km² e 5.652 habitantes, onde 2.649 vivem no meio urbano e 3.003 no meio rural. Em ambos os municípios predomina a agricultura familiar, em pequenas unidades de produção agrícola. Em Machadinho, a área média dos estabelecimentos agrícolas é 25,33 ha, sendo que 63,61\% têm menos de 20 ha e $89,38 \%$ têm menos de 50 ha. Por sua vez, em Maximiliano de Almeida, a área média é apenas 17,69 ha, sendo que 66,04\% dos estabelecimentos têm menos de 20 ha e 94,89\% têm menos de 50 ha.

Para a coleta dos dados, tanto sócio-econômicos quanto ambientais, foram aplicados 48 questionários nos dois municípios. Em cada município, foi escolhida uma microbacia e, segundo compreensão dos técnicos do escritório da EMATER no município, os agricultores foram estratificados em carentes, intermediários e consolidados. Para que houvesse aleatoriedade e representatividade, feita esta estratificação, oito agricultores de cada estrato (carentes, intermediários, consolidados) foram sorteados para a aplicação do questionário específico, totalizando 24 entrevistas em cada município. Os questionários consistem de itens que objetivam a formação da base de dados sobre diversos indicadores sócio-econômicos, bem como de indicadores de comportamentos ambientais para a preservação ou degradação dos recursos naturais.

\section{4 - Definição das variáveis utilizadas}

Diversas abordagens vêm sendo adotadas no estudo da pobreza, em diferentes regiões e diferentes contextos, envolvendo tanto aspectos 
quantitativos como aspectos qualitativos. Entretanto, tem sido freqüente o reconhecimento do caráter multidimensional da pobreza. A condição de pobreza tem sido definida de uma forma abrangente, como um fenômeno em múltiplas dimensões, com aspectos econômicos, sociais e culturais, que se caracterizam por: (a) insuficiência de renda; (b) carência ou acesso limitado a serviços destinados a satisfazer as necessidades básicas das famílias; e (c) exclusão social e discriminação devida à origem étnica ou gênero (FIDA, 2000). A mensuração da pobreza através de indicadores de apenas uma dimensão, por exemplo, a renda, pode conduzir a discrepâncias na interpretação e no entendimento do fenômeno mais amplo, multidimensional. Assim, dando seqüência aos trabalhos de Waquil e Mattos (2002, 2003), analisamos aqui um conjunto amplo de variáveis, visando melhor expressar a diversidade de condições sócio-econômicas que podem caracterizar as situações de pobreza rural no Rio Grande do Sul. Este primeiro conjunto de variáveis é definido conforme apresentado no Quadro 1, a seguir.

Da mesma forma, a degradação ambiental é um fenômeno complexo e multidimensional. Também utilizamos um conjunto amplo de variáveis ambientais, com a meta de melhor expressar a diversidade de condições que podem caracterizar as situações de degradação dos recursos naturais e do meio ambiente. Em vista da dificuldade de mensurar os níveis de degradação ambiental, analisamos aqui estas situações de forma qualitativa, a partir da observação de práticas que podem implicar em maior ou menor degradação, caracterizando desta forma um conjunto de variáveis binárias. Em todos os casos, a variável assume valor igual a zero quando as práticas implicam maior degradação, e valor igual a um quando as práticas implicam menor degradação. $\mathrm{O}$ segundo conjunto de variáveis é definido de acordo com o Quadro 2. 
Quadro 1 - Variáveis sócio-econômicas

\begin{tabular}{|c|c|c|}
\hline Nome & Definição & $\begin{array}{l}\text { Unidade de } \\
\text { medida }\end{array}$ \\
\hline RENDA & $\begin{array}{l}\text { renda anual per capita (agrícola e não-agrícola, } \\
\text { inclusive aposentadorias e pensões) }\end{array}$ & $\mathrm{R} \$$ \\
\hline TAMANH & tamanho do estabelecimento agrícola & ha \\
\hline IDADE & idade do chefe da família & anos \\
\hline ESCOL & anos de estudo do chefe da família & anos \\
\hline SAUDE & $\begin{array}{l}\text { condições de saúde da família, variando de } 1 \text { a } 5 \\
\text { conforme declaração do entrevistado; o valor } 1 \\
\text { refere-se a condições muito ruins de saúde, e o } \\
\text { valor } 5 \text { refere-se a condições muito boas }\end{array}$ & escala \\
\hline ACMERC & $\begin{array}{l}\text { acesso a mercados, variando de } 1 \text { a } 3 \text {, ou seja, } \\
1 \text { quando o agricultor possui um acesso ruim aos } \\
\text { mercados locais, seja por falta de transporte, } \\
\text { falta de estradas, ou por não ser sócio do sindicato } \\
\text { e da cooperativa, } 2 \text { quando possui acesso regular e } \\
3 \text { quando possui um bom acesso ao mercado }\end{array}$ & escala \\
\hline ACINFO & $\begin{array}{l}\text { acesso à informação, variando de } 0 \text { a } 3 \text {, isto é, } 0 \\
\text { quando o agricultor não possui nenhum } \\
\text { veículo/meio de informação, como rádio e } \\
\text { televisão, e } 3 \text { quando o agricultor, além da } \\
\text { televisão e do rádio, participa de cursos de } \\
\text { extensão ofertados pela EMATER e/ou pela } \\
\text { cooperativa e sindicato local }\end{array}$ & escala \\
\hline ACCRED & $\begin{array}{l}\text { acesso a crédito, variando de } 0 \text { quando o agricultor } \\
\text { não havia contraído financiamento nos últimos } \\
\text { cinco anos, até } 5 \text { quando o agricultor havia contraído } \\
\text { cinco financiamentos nos últimos cinco anos }\end{array}$ & escala \\
\hline ASSTEC & $\begin{array}{l}\text { assistência técnica, variando de } 1 \text { (ruim), ou seja, } \\
\text { o agricultor não recebe visitas freqüentes dos } \\
\text { técnicos da EMATER ou outro órgão assistente, até } \\
5 \text { (muito boa), onde o agricultor recebe toda a } \\
\text { assistência possível e com freqüência }\end{array}$ & escala \\
\hline BENS & $\begin{array}{l}\text { disponibilidade de bens e infraestrutura, variando } \\
\text { de } 0 \text { a } 5 \text {, dependendo do número de bens que existem } \\
\text { na casa, como telefone, banheiro, água encanada, } \\
\text { luz elétrica e geladeira }\end{array}$ & escala \\
\hline
\end{tabular}


Quadro 2 - Variáveis ambientais

\begin{tabular}{|c|c|}
\hline Nome & Definição \\
\hline AGROTX & $\begin{array}{l}=0, \text { se o indivíduo utiliza agrotóxicos } \\
=1 \text {, caso contrário }\end{array}$ \\
\hline DERRUB & $\begin{array}{l}=0, \text { se o indivíduo faz derrubada ou queimada de matas } \\
=1 \text {, caso contrário }\end{array}$ \\
\hline TERRAC & $\begin{array}{l}=0, \text { se o indivíduo não faz terraceamento } \\
=1 \text {, caso contrário }\end{array}$ \\
\hline ROTAC & $\begin{array}{l}=0 \text {, se o indivíduo não faz rotação ou consorciação de cultivos } \\
=1 \text {, caso contrário }\end{array}$ \\
\hline AD_ORG & $\begin{array}{l}=0 \text {, se o indivíduo não faz adubação orgânica } \\
=1 \text {, caso contrário }\end{array}$ \\
\hline COBERT & $\begin{array}{l}=0 \text {, se o indivíduo não utiliza cobertura verde } \\
=1 \text {, caso contrário }\end{array}$ \\
\hline CALAG & $\begin{array}{l}=0, \text { se o indivíduo não faz calagem } \\
=1, \text { caso contrário }\end{array}$ \\
\hline REFLOR & $\begin{array}{l}=0, \text { se o indivíduo não faz reflorestamento } \\
=1 \text {, caso contrário }\end{array}$ \\
\hline PD & $\begin{array}{l}=0, \text { se o indivíduo não faz plantio direto } \\
=1 \text {, caso contrário }\end{array}$ \\
\hline LIXO & $\begin{array}{l}=0 \text {, se o indivíduo não faz o manejo adequado do lixo } \\
=1 \text {, caso contrário }\end{array}$ \\
\hline
\end{tabular}

\section{5 - Perfil dos agricultores na região em estudo}

Nesta seção, iniciamos com a apresentação de algumas medidas de tendência central e de variabilidade, permitindo uma primeira aproximação sobre o perfil dos agricultores na região em estudo. A Tabela 1, apresentada a seguir, inclui os valores mínimo e máximo observados, a média e o desvio-padrão correspondentes a cada uma das variáveis, caracterizando as dimensões sócio-econômica e ambiental. Com base nestas medidas de estatística descritiva, verificamos que a renda anual per capita apresenta uma grande variabilidade nos municípios analisados, oscilando desde um mínimo de $\mathrm{R} \$ 293,00$ até um máximo de $\mathrm{R} \$$ 42.560,00. A média dos 48 entrevistados corresponde a $\mathrm{R} \$ 4.166,31$ per capita anuais, com um desvio-padrão de R \$ 6.673,04. Entre as variáveis sócio- 
econômicas, a renda é a que tem maior variabilidade, sendo a única a apresentar o coeficiente de variação ( $\mathrm{CV}=$ desvio-padrão / média) maior que um. Ainda que não seja suficiente para expressar de forma completa as situações de pobreza, esta variável já dá indicações da diversidade encontrada na região.

Tabela 1 - Medidas de tendência central e de variabilidade

\begin{tabular}{|l|c|c|c|c|}
\hline & Mínimo & Máximo & Média & Desvio-Padrão \\
\hline RENDA & 293,00 & $42.560,00$ & $4.166,31$ & $6.673,04$ \\
TAMANH & 2,00 & 47,00 & 16,77 & 9,69 \\
\hline IDADE & 29,00 & 75,00 & 49,08 & 12,07 \\
\hline ESCOL & 0,00 & 11,00 & 4,44 & 2,87 \\
\hline SAUDE & 2,00 & 5,00 & 3,00 & 0,83 \\
\hline ACMERC & 1,00 & 3,00 & 2,40 & 0,74 \\
\hline ACINFO & 0,00 & 3,00 & 2,17 & 0,75 \\
\hline ACCRED & 0,00 & 3,00 & 1,29 & 0,97 \\
\hline ASSTEC & 2,00 & 5,00 & 3,54 & 1,03 \\
\hline BENS & 0,00 & 5,00 & 3,77 & 1,31 \\
\hline AGROTX & 0,00 & 1,00 & 0,27 & 0,45 \\
\hline DERRUB & 0,00 & 1,00 & 0,21 & 0,41 \\
\hline TERRAC & 0,00 & 1,00 & 0,21 & 0,41 \\
\hline ROTAC & 0,00 & 1,00 & 0,52 & 0,50 \\
\hline AD_ORG & 0,00 & 1,00 & 0,60 & 0,49 \\
\hline COBERT & 0,00 & 1,00 & 0,85 & 0,36 \\
\hline CALAG & 0,00 & 1,00 & 0,87 & 0,33 \\
\hline REFLOR & 0,00 & 1,00 & 0,25 & 0,44 \\
\hline PD & 0,00 & 1,00 & 0,71 & 0,45 \\
\hline LIXO & 0,00 & 1,00 & 0,12 & 0,33 \\
\hline
\end{tabular}

Fonte: resultados da pesquisa.

Outras variáveis que apresentaram resultados interessantes são o tamanho do estabelecimento agrícola, a idade e escolaridade. O tamanho da unidade de produção varia de 2,00 a 47,00 hectares, com média igual 16,77 hectares, situação que se aproxima da realidade da região conforme apontado na seção que caracteriza a região de estudo. Por sua vez, a idade dos entrevistados varia desde 29 até 75 anos, mostran- 
do a existência tanto de agricultores jovens como de idosos. Já a escolaridade apresenta um mínimo de 0 até um máximo de 11 anos de estudo, com uma média de 4,44 e um desvio-padrão de 2,87 anos de estudo.

As demais variáveis na dimensão sócio-econômica, medidas como escalas, têm seus limites inferiores e superiores pré-definidos. As variáveis acesso a mercados, acesso à informação, assistência técnica e disponibilidade de bens apresentam valores médios mais próximos aos limites superiores das escalas, indicando melhores condições de vida, a partir do acesso a estes itens, dos indivíduos entrevistados. Por outro lado, o acesso a crédito apresenta média bem mais próxima ao limite inferior da escala, sugerindo que esta pode ser uma restrição importante, diferenciando os agricultores e podendo inclusive impactar a adoção de práticas que afetam a degradação ambiental.

Com relação às variáveis da dimensão ambiental, sempre os valores mínimo e máximo correspondem a 0 e 1, indicando que há indivíduos que utilizam práticas que mais degradam o ambiente, assim como indivíduos que não utilizam tais práticas. As médias destas variáveis binárias representam o percentual de observações cuja variável assume o valor um, ou seja, o percentual de indivíduos que adotam práticas preservacionistas.

As variáveis uso de agrotóxicos, derrubadas, terraceamento, reflorestamento e manejo do lixo são as que apresentam as menores médias (entre 0,12 e 0,27), indicando que a maior parte dos indivíduos usa agrotóxicos e pratica derrubadas, mas não faz terraceamento, reflorestamento e manejo adequado do lixo, resultando em maior degradação do meio ambiente. Por outro lado, as variáveis cobertura verde do solo, calagem e plantio direto têm as maiores médias (entre 0,71 e 0,87), o que sugere que a maior parte dos indivíduos adota tais práticas de cultivo, resultando em menor degradação do meio ambiente com relação a estes quesitos. As variáveis rotação de cultivos e adubação orgânica apresentam valores intermediários para as médias $(0,52$ e 0,60), assim como os maiores desvios-padrão, indicando maior variabilidade entre as observações.

Desta caracterização inicial, com base nas medidas de tendência central e de variabilidade apresentadas acima, podemos já sugerir que em vista da necessidade de gerar renda em pequenos estabelecimentos agrí- 
colas, e do acesso a mercados, informação e assistência técnica, geralmente os agricultores da região adotam práticas de cultivo mais intensivas, promovendo o uso de agrotóxicos e derrubadas, mas também cobertura verde, calagem e plantio direto. Com isto, desde já podemos sugerir uma relação ambígua entre a dimensão sócio-econômica e a dimensão ambiental, ou seja, entre pobreza rural e degradação ambiental.

\section{6 - O modelo Probit ${ }^{5}$}

Neste artigo, estimamos a relação entre pobreza rural e degradação ambiental, utilizando os indicadores sócio-econômicos e ambientais descritos na seção anterior. Com o objetivo de identificar a existência ou não e, quando pertinente, verificar o sentido das possíveis relações entre os indicadores sócio-econômicos e os indicadores ambientais, estimamos diversos modelos não-lineares de regressão (probit), tendo variáveis binárias como dependentes, expressando a degradação ambiental, e os diversos indicadores sócio-econômicos como variáveis independentes, expressando as situações de pobreza rural.

Convém relembrar que observamos a degradação ambiental de forma qualitativa, expressando-a com base em um conjunto de diversas variáveis binárias. Em todos os casos, tomamos como valor igual a zero quando as práticas implicam em maior degradação, e valor igual a um quando as práticas implicam em menor degradação ambiental. Por outro lado, as variáveis independentes utilizadas são aquelas apresentadas na seção anterior, que permitem a caracterização das condições sócioeconômicas dos indivíduos. Como regra geral, valores mais elevados destas variáveis apontam para melhores condições de vida dos indivíduos. Assim, quando os sinais dos coeficientes estimados nos modelos apresentados abaixo são positivos, a relação entre pobreza rural e degradação ambiental é direta, ou seja, maior pobreza relaciona-se com maior degradação, e vice-versa. Por outro lado, quando os coeficientes

\footnotetext{
${ }^{5}$ A apresentação dos modelos nesta seção é baseada em Hill, Griffiths e Judge (2003) e Maddala (1992). De acordo com o Dicionário Brasileiro de Estatística, o modelo também é referido como próbite.
} 
são negativos, a relação é inversa, ou seja, maior pobreza relaciona-se com menor degradação do meio ambiente, e vice-versa.

Na presença de variáveis dependentes binárias, o modelo mais simples é o modelo linear de probabilidade:

$$
y=\beta_{0}+\beta_{1} x_{1}+\ldots+\beta_{k} x_{k}+e
$$

Sendo $p$ a probabilidade de $y$ assumir o valor igual a um:

$$
E(y)=p=\beta_{0}+\beta_{1} x_{1}+\ldots+\ldots \beta_{k} x_{k}
$$

Neste modelo, os coeficientes estimados expressam o efeito de variações unitárias nas variáveis independentes sobre a probabilidade da variável dependente assumir o valor um. O problema é que estes efeitos são constantes, e à medida em que xi aumenta, a probabilidade $p$ continua a aumentar (quando $\beta_{\mathrm{i}}$ é positivo, caso contrário continua a diminuir) a uma razão constante. Entretanto, como $0 \leq p \leq 1$, é impossível ter uma taxa constante de crescimento. Além disto, o modelo linear de probabilidade apresenta erros heterocedásticos, tal que os coeficientes estimados não são eficientes. Assim, os testes de hipóteses e intervalos de confiança podem ser inválidos.

Para contornar estes problemas, consideramos os modelos não-lineares probit e logit. Nestes casos, a inclinação não é constante. As probabilidades são restringidas ao intervalo $[0,1]$, pela utilização de funções densidade de probabilidade. A função probit está relacionada com a distribuição de probabilidade normal padronizada, enquanto a função logit está relacionada com a distribuição logística. Como são modelos não-lineares, a estimação dos coeficientes deve ser feita pelo método de máxima verossimilhança. Em geral, os coeficientes estimados nos modelos probit e logit são ligeiramente diferentes e a escolha entre eles pode ser feita de acordo com a conveniência. No pre-sente artigo, optamos pelo modelo probit, considerando então que os erros têm distribuição normal. Assim,

$$
p=F=\left(\beta_{0}+\beta_{1} x_{1}+\ldots+\beta_{k} x_{k}\right)
$$


onde novamente $p$ é a probabilidade de $y$ assumir valor igual a um e $F$ é a função probit, não-linear nos $\beta_{\mathrm{i}}$. O efeito de uma variação unitária em $x_{i}$ sobre a probabilidade $p$ de $y$ ser igual a um é dado por:

$$
\frac{\partial p}{\partial x_{i}}=\frac{\partial F(t)}{\partial(t)} \cdot \frac{\partial t}{\partial x_{i}}=f(\cdot) \beta_{i}
$$

A partir disto,

(a) como $f(\cdot)$ é uma função densidade de probabilidade, seu valor é sempre positivo. Logo, o sinal de $\partial p / \partial x_{i}$ é determinado pelo sinal de $\beta_{\mathrm{i}}$;

(b) à medida que $x_{i}$ varia, o valor de $f(\cdot)$ também varia. Desta forma, o efeito de uma variação unitária nas variáveis independentes sobre a probabilidade da variável dependente, depende dos níveis das variáveis independentes. Portanto, para estimar o efeito dos coeficientes do modelo probit é necessário escolher algum nível para as variáveis independentes como referência.

\section{7 - Resultados}

Nesta seção, discutimos os resultados da estimação das dez regressões, aplicando o modelo probit descrito na seção anterior e tendo, em cada regressão, uma variável dependente binária que expressa a degradação ambiental, em função das demais dez variáveis independentes que expressam as situações de pobreza rural. Os coeficientes estimados, assim como os erros-padrão utilizados para testar hipóteses sobre os coeficientes, são apresentados em anexo, ao final do artigo.

É importante esclarecer que não temos o objetivo de interpretar cada coeficiente estimado, nem mensurar o efeito que cada variável exerce sobre a probabilidade das variáveis dependentes assumirem valor igual a um (isto é, a probabilidade de os indivíduos utilizarem práticas que resultam em menos degradação ambiental). Temos, sim, o objetivo de identificar a existência ou não de relação entre os indicadores sócio-econômicos e os indicadores ambientais, assim como verificar o sentido de tais relações.

Para isto, fizemos os testes de hipóteses, identificando quais coefici- 
entes diferem de zero, a um nível de significância de até $20 \%$. Para estes coeficientes, apresentamos no quadro abaixo os sinais encontrados.

Quadro 3 - Sinais dos coeficientes estimados

\begin{tabular}{|c|c|c|c|c|c|c|c|c|c|}
\hline RENDA & TAMANH & IDADE & ESCOL & SAUDE & ACMERC & ACINFO & ACCRED & ASSTEC & BENS \\
\hline AGROTX & - & - & & & + & & - & - & - \\
\hline DERRUB & - & - & + & & & & & & + \\
\hline TERRAC & & & + & + & & & & & \\
\hline ROTAC & & & & & & + & + & & \\
\hline AD_ORG & & & & & + & & + & - & \\
\hline COBERT & & & & & & & & + & + \\
\hline CALAG & & - & & & & + & & - & + \\
\hline REFLOR & & & + & & - & - & + & & \\
\hline PD & & & & & & & & & + \\
\hline LIXO & & - & & + & & & & & + \\
\hline
\end{tabular}

Fonte: resultados da pesquisa.

Observando primeiramente os sinais nas linhas, chama-nos a atenção a predominância de sinais negativos na primeira linha, que corresponde à variável dependente que expressa o uso ou não de agrotóxicos. O aumento nos níveis das variáveis independentes relaciona-se negativamente com a probabilidade desta variável dependente assumir valor igual a um. Assim, à medida que melhoram as condições sócio-econômicas (reduzindo as situações de pobreza rural), diminui a probabilidade dos indivíduos não utilizarem agrotóxicos (aumentando as situações de degradação ambiental). Este resultado aponta para uma relação inversa entre pobreza e degradação ambiental.

Nas demais linhas, algumas vezes observa-se a alternância de sinais positivos e negativos, sugerindo uma relação ambígua entre pobreza rural e degradação do meio ambiente. Outras vezes observa-se a predominância de sinais positivos, como por exemplo nas linhas correspondentes às variáveis que expressam práticas culturais como terraceamento, rotação de cultivos e cobertura do solo. Nestes casos, níveis mais elevados das variáveis independentes relacionam-se positivamente com a probabilidade dos indivíduos realizarem tais práticas. Agora, estes re- 
sultados apontam para uma relação direta entre pobreza e degradação ambiental, isto é, a melhoria das condições sócio-econômicas resulta também na adoção de práticas mais adequadas à preservação ambiental.

Por outro lado, quando observamos os resultados nas colunas, chama-nos a atenção a ocorrência de sinais negativos nas duas primeiras e na oitava coluna, que correspondem às variáveis independentes renda, tamanho do estabelecimento e acesso a crédito. Estes sinais negativos indicam que o aumento nos níveis destas variáveis tende a diminuir a probabilidade das variáveis dependentes assumirem valor igual a um, mais especificamente com o maior uso de agrotóxicos, mais derrubadas e menos adubação orgânica. São justamente os maiores estabelecimentos, e os de maior renda e com maior acesso a crédito, que utilizam agrotóxicos mais intensivamente, provocando maior degradação do meio ambiente.

Na terceira coluna aparece um resultado que, de certa forma, nos surpreende. Os sinais positivos sugerem que quanto mais idosos os indivíduos, maior a probabilidade das variáveis dependentes igualaremse a um. Desta forma, a partir desta base de dados, pode-se inferir que são os jovens os que mais degradam o ambiente, não demonstrando preocupação com a sustentabilidade dos processos produtivos para as futuras gerações.

Com relação à variável independente escolaridade, apenas um dos coeficientes estimados mostrou-se significativamente diferente de zero (positivo), como se pode observar no quadro acima. Entretanto, em quase todos os demais casos, os sinais também são positivos, conforme apresentado nas tabelas em anexo. Estes resultados confirmam a importância da educação formal para a preservação ambiental, apontando para o aumento das práticas preservacionistas à medida que aumentam os níveis de escolaridade.

Também as variáveis acesso à informação e assistência técnica mostram predominância de coeficientes positivos. Quanto maior o acesso à informação e quanto maior a prestação de assistência técnica (pública ou privada), maior a probabilidade das variáveis dependentes assumirem valor igual a um, ou seja, maior a probabilidade de os indivíduos adotarem práticas preservacionistas e assim menor a degradação ambiental. 
Ainda assim, em diversas situações ocorre a alternância de sinais positivos e negativos, mais uma vez sugerindo a ambigüidade da relação entre pobreza rural e degradação ambiental. Observando o quadro completo, podemos verificar um total de 18 sinais positivos e 13 negativos.

Estes resultados são corroborados pelos resultados obtidos com a estimação das regressões utilizando o modelo linear de probabilidade. Apesar das suas limitações para a inferência estatística e previsão, o modelo linear pode ser aplicado para verificar o sentido das relações estudadas. Os resultados do modelo linear de probabilidade, não apresentados neste artigo, confirmam os sinais discutidos acima.

Desta forma, podemos identificar algumas relações entre indicadores específicos, mas devemos refutar a hipótese de uma relação, seja direta ou inversa, entre os fenômenos mais amplos, multidimensionais, que caracterizam a pobreza rural e a degradação ambiental.

\section{8 - Conclusões}

O artigo analisa as relações entre dois fenômenos complexos: a pobreza rural e a degradação ambiental, questionando se o "círculo vicioso", freqüentemente mencionado na literatura sobre o tema, é verificado nos municípios de Machadinho e Maximiliano de Almeida, situados na região Noroeste do Rio Grande do Sul. Utilizamos um conjunto amplo de indicadores sócio-econômicos e ambientais, buscando melhor expressar a diversidade de situações, envolvendo diferentes tipos de pobreza, assim como diferentes tipos de degradação do meio ambiente. A análise estatística descritiva, com a caracterização das medidas de tendência central e de variabilidade, ilustra esta diversidade de situações na região.

Os resultados obtidos a partir da estimação de modelos não-lineares de regressão (probit) sugerem a refutação da relação entre pobreza e degradação, seja direta ou inversa. Em diversas situações encontramos sinais positivos e negativos, apontando para a ambigüidade da relação entre pobreza rural e degradação ambiental. Esta é uma contribuição que o presente artigo traz: a aplicação do modelo probit para estudar as relações entre pobreza e degradação, até então inédita na literatura sobre o tema. 
Estes resultados confirmam aqueles apontados por Broad (1994), assim como por Reardon e Vosti (1995), os quais concluem:

Not all environmental degradation in developing countries is linked to poverty; for example, pollution as an externality of the agriculture of richer farmers or forest or commons overexploitation by large and capital-intensive lumber and cattle operations can ravage the environment without the poor's lifting a hand.

Desta forma, podemos concluir que a redução da pobreza rural não implica, necessariamente, em redução da degradação ambiental; também a redução da degradação ambiental não implica, necessariamente, em redução da pobreza no espaço rural. Existe uma série de variáveis, como as condições de acesso a mercados, informação, crédito e assistência técnica, que podem condicionar estas relações, e assim influenciar as estratégias adotadas pelos agricultores familiares.

Estes condicionantes podem ser alterados pela proposição e implementação de políticas públicas, permitindo o alcance de ambos objetivos simultaneamente: o alívio da pobreza rural e a redução da degradação ambiental. Podemos citar aqui, apenas como ilustração das possíveis formas de intervenção do Estado, a promoção de mercados específicos para os produtos da agricultura familiar, o investimento em infra-estrutura complementar, e a pesquisa para viabilizar o uso de tecnologias adequadas às diferentes situações, que permitam ganhos de produtividade aliados à preservação dos recursos naturais.

\section{9 - Referências Bibliográficas}

Alier, J. M. Da economia ecológica ao ecologismo popular. Editora da FURB, 1998. 402p.

Barbier, E. “The economic linkages between rural poverty and land degradation: some evidence from Africa”. Agriculture, Ecosystems and Environment, v. 82, p. 355-370, 2000. 
Broad, R. "The poor and the environment: friends or foes?" World Development, v. 22, n. 6, p. 811-22, 1994.

Cavendish, W. Empirical regularities in the poverty-environment relationship of African rural households. www.econ.ox.ac.uk/ csaeadmin/workingpapers/pdfs. 1999. 26p.

Comissão Mundial sobre Meio Ambiente e Desenvolvimento. Nosso Futuro Comum. 2. ed. Rio de Janeiro: Editora da Fundação Getúlio Vargas, 1991. 430p.

Echeverria, R. G. Elementos estratégicos para la reducción de la pobreza rural en América Latina y el Caribe. Washington: BID, 1998. $39 \mathrm{p}$.

Echeverria, R. G. Opciones para reducir la pobreza rural en América Latina y el Caribe. Revista de la CEPAL, 2000.

FIDA - International Fund for Agricultural Development. Hacia una region sin pobres rurales. Santiago: FIDA, 2000.

Hill, R. C.; Griffiths, W. E.; Judge, G. G. Econometria. 2. ed. São Paulo: Saraiva, 2003.

Maddala, G. S. Introduction to econometrics. $2^{\text {nd }}$ edition. New York: Macmillan Publishing Company, 1992.

Meza, R. J.; Southgate, D.; Vega, C. G. Rural development, poverty and agricultural land use in El Salvador. www.agecon.ag.ohiostate/programs. 2002. 23p.

Reardon, T. and Vosti, S. "Links between rural poverty and the environment in developing countries: asset categories and investment poverty”. World Development, v. 23, n. 9, p. 1495-1506, 1995. 
Schneider, S.; Waquil, P. D. "Caracterização sócio-econômica dos municípios gaúchos e desigualdades regionais”. Revista de Economia e Sociologia Rural, Brasília, v. 39, n. 3, p. 117-142, 2001.

Waquil, P. D.; Mattos, E. J. "Distribuição de renda no Rio Grande do Sul: um comparativo entre o rural e o urbano". Revista Ensaios FEE, Porto Alegre, RS, v. 23, n. especial, p. 621-644, 2002.

Waquil, P. D.; Mattos, E. J. Pobreza rural e urbana no Rio Grande do Sul: uma análise além da renda. Porto Alegre: PGDR/UFRGS, 2003. (Texto para discussão, aceito para publicação na Revista REDES, editada pelo Programa de Pós-Graduação em Desenvolvimento Regional da UNISC).

Recebido em maio de 2003 e revisto em abril de 2004. 


\section{Anexos}

Regressão 01: Y = AGROTX

\begin{tabular}{|lcc|}
\hline Variável & $\begin{array}{c}\text { Coeficiente } \\
\text { estimado }\end{array}$ & $\begin{array}{c}\text { Erro- } \\
\text { padrão }\end{array}$ \\
\hline RENDA & $-0,00035$ & 0,00021 \\
\hline TAMANH & $-0,16828$ & 0,10166 \\
\hline IDADE & 0,03016 & 0,03477 \\
\hline ESCOL & 0,03843 & 0,21555 \\
\hline SAUDE & 1,49828 & 0,65566 \\
\hline ACMERC & $-0,18987$ & 0,72603 \\
\hline ACINFO & $-1,24628$ & 0,77158 \\
\hline ACCRED & $-1,06469$ & 0,53808 \\
\hline ASSTEC & $-0,64259$ & 0,51555 \\
\hline BENS & 0,45839 & 0,56481 \\
\hline TERMO & & \\
CONSTANTE & 0,90786 & 2,41378 \\
\hline
\end{tabular}

Pearson Goodness-of-Fit Chi Square $=22,485$
Regressão 03: Y = TERRAC

\begin{tabular}{|lcc|}
\hline Variável & $\begin{array}{c}\text { Coeficiente } \\
\text { estimado }\end{array}$ & $\begin{array}{c}\text { Erro- } \\
\text { padrão }\end{array}$ \\
\hline RENDA & 0,00003 & 0,00004 \\
\hline TAMANH & $-0,03152$ & 0,03613 \\
IDADE & 0,05818 & 0,03521 \\
\hline ESCOL & 0,23338 & 0,14408 \\
\hline SAUDE & $-0,28157$ & 0,39674 \\
\hline ACMERC & $-0,60211$ & 0,71796 \\
\hline ACINFO & 0,38606 & 0,53672 \\
\hline ACCRED & $-0,36545$ & 0,37475 \\
\hline ASSTEC & 0,11073 & 0,30234 \\
\hline BENS & 0,49446 & 0,42128 \\
\hline TERMO & & \\
CONSTANTE & $-6,60478$ & 2,64004 \\
\hline
\end{tabular}

Regressão 02: Y = DERRUB

\begin{tabular}{|lcc|}
\hline Variável & $\begin{array}{c}\text { Coeficiente } \\
\text { estimado }\end{array}$ & $\begin{array}{c}\text { Erro- } \\
\text { padrão }\end{array}$ \\
\hline RENDA & $-0,00053$ & 0,00043 \\
\hline TAMANH & $-0,25594$ & 0,16050 \\
\hline IDADE & 0,22997 & 0,11782 \\
\hline ESCOL & 0,36067 & 0,38531 \\
\hline SAUDE & 0,92288 & 0,87097 \\
\hline ACMERC & 0,34703 & 1,31633 \\
\hline ACINFO & 1,11044 & 1,18577 \\
\hline ACCRED & $-1,02661$ & 0,90662 \\
\hline ASSTEC & 2,02150 & 1,41800 \\
\hline BENS & $-0,33846$ & 0,80430 \\
\hline TERMO & & \\
CONSTANTE & $-21,15183$ & 9,65815 \\
\hline
\end{tabular}

Pearson Goodness-of-Fit Chi Square $=13,646$
Regressão 04: Y = ROTAC

\begin{tabular}{|lcc|}
\hline Variável & $\begin{array}{c}\text { Coeficiente } \\
\text { estimado }\end{array}$ & $\begin{array}{c}\text { Erro- } \\
\text { padrão }\end{array}$ \\
\hline RENDA & $-0,00003$ & 0,00004 \\
\hline TAMANH & 0,01715 & 0,03250 \\
\hline IDADE & $-0,02251$ & 0,02605 \\
\hline ESCOL & $-0,09752$ & 0,12255 \\
\hline SAUDE & $-0,20880$ & 0,31749 \\
\hline ACMERC & 0,72388 & 0,52092 \\
\hline ACINFO & 0,53633 & 0,44842 \\
\hline ACCRED & $-0,15213$ & 0,27460 \\
\hline ASSTEC & 0,21476 & 0,26008 \\
\hline BENS & 0,12122 & 0,32293 \\
\hline $\begin{array}{l}\text { TERMO } \\
\text { CONSTANTE }\end{array}$ & $-1,89880$ & 1,72025 \\
\hline
\end{tabular}

Pearson Goodness-of-Fit Chi Square $=48,120$ 
Regressão 05: Y = AD_ORG

\begin{tabular}{|lcc|}
\hline Variável & $\begin{array}{c}\text { Coeficiente } \\
\text { estimado }\end{array}$ & $\begin{array}{c}\text { Erro- } \\
\text { padrão }\end{array}$ \\
\hline RENDA & 0,00001 & 0,00007 \\
\hline TAMANH & 0,02694 & 0,03898 \\
\hline IDADE & 0,02871 & 0,02865 \\
\hline ESCOL & 0,16084 & 0,17464 \\
\hline SAUDE & 0,46333 & 0,34451 \\
\hline ACMERC & $-0,38923$ & 0,54567 \\
\hline ACINFO & 0,76953 & 0,46443 \\
\hline ACCRED & $-0,45567$ & 0,31802 \\
\hline ASSTEC & $-0,02879$ & 0,28504 \\
\hline BENS & 0,34964 & 0,34073 \\
\hline $\begin{array}{l}\text { TERMO } \\
\text { CONSTANTE }\end{array}$ & $-4,93284$ & 2,10293 \\
\hline
\end{tabular}

Pearson Goodness-of-Fit Chi Square $=39,469$

Regressão 07: Y $=$ CALAG
\begin{tabular}{|lcc|}
\hline Variável & $\begin{array}{c}\text { Coeficiente } \\
\text { estimado }\end{array}$ & $\begin{array}{c}\text { Erro- } \\
\text { padrão }\end{array}$ \\
\hline RENDA & 0,00030 & 0,00048 \\
\hline TAMANH & $-0,13185$ & 0,06889 \\
\hline IDADE & $-0,01609$ & 0,04375 \\
\hline ESCOL & 0,10355 & 0,26681 \\
\hline SAUDE & $-0,51374$ & 0,47821 \\
\hline ACMERC & 1,66420 & 1,23326 \\
\hline ACINFO & $-0,41071$ & 0,59163 \\
\hline ACCRED & $-0,67807$ & 0,52102 \\
\hline ASSTEC & 0,79984 & 0,65045 \\
\hline BENS & 0,14869 & 0,47453 \\
\hline $\begin{array}{l}\text { TERMO } \\
\text { CONSTANTE }\end{array}$ & $-0,25671$ & 2,44427 \\
\hline
\end{tabular}

Pearson Goodness-of-Fit Chi Square $=24,929$
Regressão 06: $\mathrm{Y}=$ COBERT

\begin{tabular}{|lcc|}
\hline Variável & $\begin{array}{c}\text { Coeficiente } \\
\text { estimado }\end{array}$ & $\begin{array}{c}\text { Erro- } \\
\text { padrão }\end{array}$ \\
\hline RENDA & 0,00066 & 0,00101 \\
\hline TAMANH & $-0,23437$ & 0,41002 \\
\hline IDADE & 0,26302 & 0,25414 \\
\hline ESCOL & 0,30027 & 1,08239 \\
\hline SAUDE & 1,19595 & 2,90239 \\
\hline ACMERC & $-2,10037$ & 2,52721 \\
\hline ACINFO & $-0,94059$ & 1,40623 \\
\hline ACCRED & $-1,20427$ & 1,07289 \\
\hline ASSTEC & 2,84642 & 1,89891 \\
\hline BENS & 3,16969 & 2,35391 \\
\hline TERMO & & \\
CONSTANTE & $-23,70012$ & 19,56538 \\
\hline
\end{tabular}

Pearson Goodness-of-Fit Chi Square $=9,104$
Regressão 08: Y = REFLOR

\begin{tabular}{|lcc|}
\hline Variável & $\begin{array}{c}\text { Coeficiente } \\
\text { estimado }\end{array}$ & $\begin{array}{c}\text { Erro- } \\
\text { padrão }\end{array}$ \\
\hline RENDA & $-0,00010$ & 0,00012 \\
\hline TAMANH & 0,06485 & 0,05469 \\
\hline IDADE & 0,06896 & 0,04079 \\
\hline ESCOL & 0,08081 & 0,22216 \\
\hline SAUDE & $-1,62175$ & 0,55406 \\
\hline ACMERC & $-1,53630$ & 0,94696 \\
\hline ACINFO & 1,50779 & 0,71945 \\
\hline ACCRED & 0,24118 & 0,38351 \\
\hline ASSTEC & 0,06163 & 0,45664 \\
\hline BENS & $-0,15305$ & 0,41297 \\
\hline $\begin{array}{l}\text { TERMO } \\
\text { CONSTANTE }\end{array}$ & $-0,41076$ & 2,28514 \\
\hline
\end{tabular}

Pearson Goodness-of-Fit Chi Square $=73,280$ 
Regressão 09: $\mathrm{Y}=\mathrm{PD}$

\begin{tabular}{|lcc|}
\hline Variável & $\begin{array}{c}\text { Coeficiente } \\
\text { estimado }\end{array}$ & $\begin{array}{c}\text { Erro- } \\
\text { padrão }\end{array}$ \\
\hline RENDA & 0,00008 & 0,00009 \\
\hline TAMANH & $-0,01149$ & 0,03442 \\
\hline IDADE & $-0,00631$ & 0,02536 \\
\hline ESCOL & $-0,13825$ & 0,13031 \\
\hline SAUDE & $-0,29708$ & 0,3344 \\
\hline ACMERC & $-0,02125$ & 0,51568 \\
\hline ACINFO & 0,21433 & 0,43581 \\
\hline ACCRED & 0,23063 & 0,29250 \\
\hline ASSTEC & 0,13293 & 0,28223 \\
\hline BENS & 0,46376 & 0,32169 \\
\hline $\begin{array}{l}\text { TERMO } \\
\text { CONSTANTE }\end{array}$ & $-0,55768$ & 1,70476 \\
\hline
\end{tabular}

Pearson Goodness-of-Fit Chi Square $=41,549$

Regressão 10: Y $=$ LIXO
\begin{tabular}{|lcc|}
\hline Variável & $\begin{array}{c}\text { Coeficiente } \\
\text { estimado }\end{array}$ & $\begin{array}{c}\text { Erro- } \\
\text { padrão }\end{array}$ \\
\hline RENDA & 0,00003 & 0,00016 \\
\hline TAMANH & $-0,12698$ & 0,10054 \\
\hline IDADE & 0,03767 & 0,07112 \\
\hline ESCOL & $-0,14739$ & 0,27172 \\
\hline SAUDE & 1,54784 & 1,23374 \\
\hline ACMERC & -- & -- \\
\hline ACINFO & 0,68152 & 1,12545 \\
\hline ACCRED & 0,22095 & 0,62852 \\
\hline ASSTEC & 0,09508 & 0,69614 \\
\hline BENS & 2,16975 & 1,31589 \\
\hline $\begin{array}{l}\text { TERMO } \\
\text { CONSTANTE }\end{array}$ & $-17,62127$ & 8,82889 \\
\hline
\end{tabular}

Pearson Goodness-of-Fit Chi Square $=19,897$ 